\title{
TU/e EnNHONEN

\section{A study of the adsorption activities of silanol surface structures on a fused silica model substrate by combining 29Si CP MAS NMR and inverse gas chromatographic data}

\author{
Citation for published version (APA): \\ Scholten, A. B., Janssen, J. G. M., Haan, de, J. W., \& Cramers, C. A. (1994). A study of the adsorption activities \\ of silanol surface structures on a fused silica model substrate by combining 29Si CP MAS NMR and inverse gas \\ chromatographic data. Journal of High Resolution Chromatography, 17(2), 77-84. \\ https://doi.org/10.1002/jhrc.1240170207
}

DOI:

10.1002/jhrc. 1240170207

Document status and date:

Published: 01/01/1994

\section{Document Version:}

Publisher's PDF, also known as Version of Record (includes final page, issue and volume numbers)

\section{Please check the document version of this publication:}

- A submitted manuscript is the version of the article upon submission and before peer-review. There can be important differences between the submitted version and the official published version of record. People interested in the research are advised to contact the author for the final version of the publication, or visit the DOI to the publisher's website.

- The final author version and the galley proof are versions of the publication after peer review.

- The final published version features the final layout of the paper including the volume, issue and page numbers.

Link to publication

\footnotetext{
General rights

- You may freely distribute the URL identifying the publication in the public portal. follow below link for the End User Agreement:

www.tue.nl/taverne

\section{Take down policy}

If you believe that this document breaches copyright please contact us at:

openaccess@tue.nl

providing details and we will investigate your claim.
}

Copyright and moral rights for the publications made accessible in the public portal are retained by the authors and/or other copyright owners and it is a condition of accessing publications that users recognise and abide by the legal requirements associated with these rights.

- Users may download and print one copy of any publication from the public portal for the purpose of private study or research.

- You may not further distribute the material or use it for any profit-making activity or commercial gain

If the publication is distributed under the terms of Article 25fa of the Dutch Copyright Act, indicated by the "Taverne" license above, please 


\title{
A Study of the Adsorption Activities of Silanol Surface Structures on a Fused Silica Model Substrate by Combining ${ }^{29}$ Si CP MAS NMR and Inverse Gas Chromatographic Data
}

\author{
Alex B. Scholten*, Hans-Gerd Janssen, Jan W. de Haan, and Carel A. Cramers \\ Eindhoven University of Technology, Laboratory of Instrumental Analysis, P.O. Box 513, 5600 MB Eindhoven, The Netherlands
}

Key Words:

Fused silica model substrates

Adsorption characteristics

Surface $\mathrm{OH}$ distribution

Inverse gas-solid chromatography

${ }^{29}$ Si CP MAS NMR

\section{Summary}

The possibilities of inverse gas-solid chromatography (IGC) in obtaining chromatographic data on fumed silica were examined. Aerosil A-200, a fused silica model substrate in ${ }^{29}$ Si nuclear magnetic resonance analysis, was trimethylsilylated to different degrees. IGC was used to very reproducibly determine the free specific energies of adsorption of several functionalized probe solutes. Hydrogen bonding solutes have a free specific energy of adsorption that is at least about $50 \%$ higher than that of non-hydrogen bonding probe solutes. NMR was used in combination with elemental analysis to calculate surface concentrations of the different chemical surface structures. IGC data and surface concentrations were combined in order to determine the contribution of each type of surface structure to the total free specific adsorption energy. It could be concluded that residual silanols from the reaction of dihydroxydisiloxysiloxane $\left(Q_{2}\right.$ groups) with trimethylchlorosilane possess a higher adsorption activity than the silanols initially present.

\section{Introduction}

In 1979 Dandeneau and Zerenner demonstrated the superiority of fused silica chromatographic capillaries to glass capillaries if the activity of the capillary wall could be reduced [1]. Since then, a large number of articles dealing with the deactivation of fused silica capillaries has been published. By now there are numerous deactivation procedures that either chemically derivatize the active silanol sites or sterically mask them to assure good chromatographic performance. Nevertheless, there is still a lack of fundamental knowledge of the course of the deactivation process and the resulting physico-chemical properties of the silica surface [2]. A large proportion of the existing deactivation procedures is a result of trial and error in method development and optimization. The same is true for the treatment of porous silica gels that are used as substrates in the preparation of stationary phases for high performance liquid chromatography.

Maciel and Sindorf were the first to demonstrate that ${ }^{29} \mathrm{Si}$ cross-polanization magic-angle-spinning nuclear magnetic resonance $(\mathrm{CP}$ MAS NMR) is a suitable technique for identifying surface structures of silica materials [3]. Chromatographers saw the importance of this development and subsequently, research was done in which the relation between the chemical surface structures as detected by NMR and the chromatographic characteristics of HPLC phases was discussed [4]. However, the low specific surface area of fused silica capillaries does not meet the requirements of the CP MAS NMR technique. For this reason, in our laboratory the use of fumed silica as a model substrate for fused silica was proposed [5]. Fumed silica (e.g. Aerosil A-200) is assumed to have surface properties very similar to fused silica, as it is a non porous, essentially amorphous silica of high purity and it is produced at the same high temperatures at which fused silica capillanies are drawn. More important, its specific surface area approximates that of porous silica gels (200 $\mathrm{m}^{2} / \mathrm{g}$ ) which makes it suitable for ${ }^{29} \mathrm{Si}$ CP MAS NMR analysis. In analogy with the maximization of the silanol surface concentration in fused silica capillaries by leaching procedures (mostly with $\mathrm{HF}$ solutions), the silanol surface concentration of fumed silica can be maximized by treatment with water at elevated temperatures (see Section 2.3)

CP MAS NMR data of deactivated fumed silica have never been directly linked to the chromatographic behavior of fused silica capillary columns. Thus, the question remains whether the fumed silica surface is indeed a suitable model for the surface of fused silica inside chromatographic capillaries. In the present study, the possibilities of inverse gas-solid chromatography in obtaining information on the chromatographic behavior of Aerosil particles that have been partially trimethylsilylated will be evaluated. Trimethylsilylation was chosen as the deactivation process because it is relatively simple and straightforward, resulting in only a few possible different surface silanol structures. Then an attempt is made to determine the contribution of each of these surface structures to the total adsorption activity. In a future study, inverse gas chromatographic data on fused silica capillaries, treated in the same way as the Aerosil, should enable validation of fumed silica as a model substrate for the fused silica capillary wall.

\section{Theory}

\subsection{Inverse Gas Chromatography (IGC)}

In everyday chromatography, known stationary phases are used to separate the unknown components of a mixture. In inverse chromatography one studies the elution behavior of probe solutes with known physico-chemical parameters (like boiling point, dipole moment, electronic structure etc.) to investigate the unknown stationary phase. There are two classes of inverse gas chromatographic experiments; those performed at finite concentration for adsorption isotherm measurements and those at infinite dilution for the determination of thermodynamic parameters. These experiments have been performed on a variety of materials, including silicas [6-11]. Some principles of IGC will be discussed below.

\subsubsection{IGC at Finite Concentration}

The shape of the adsorption isotherm of a solute on a stationary phase determines the peak profile in chromatography. Virtually all stationary phases possess some surface inhomogeneity, which means that the adsorption sites differ in adsorption probability, resulting in curved isotherms. The adsorption sites with the highest activity, on which the solutes experience the strongest retention, 
are occupied already at low gas-phase concentrations of the solutes. Therefore, higher concentrations will elute faster and consequently tailing peaks are observed in the chromatogram. The Elution of Characteristic Points (ECP) method provides a mathematical way of calculating the adsorption isotherm from the elution profile. It is even possible to derive from an accurate isotherm the energy distribution function of a surface, giving the number of sites as a function of their adsonption energy [12]. In this study ECP isotherms will only be discussed qualitatively because of practical limitations. A mathematical description of the ECP method is beyond the scope of this work. For a detailed discussion the reader is referred to ref. [13].

\subsubsection{IGC at Infinite Dilution}

When the probe solutes are introduced into the chromatographic system in very small amounts, it can be assumed that the adsorbed molecules show no mutual interactions. Due to the dilution in the gas phase immediately after injection, every probe molecule adsorbs and desorbs from a clean surface, independently of other probe molecules. This implies that the adsorption isotherm is linear and that the elution signal is symmetrical. When this is the case, the net retention volumes of the test components are a measure of their free energy of adsorption to the solid phase. This energy can be thought of as consisting of two components; the energy associated with the non-specific London forces between solute and solid phase and the energy associated with specific interactions. This is expressed in equation (1).

$\Delta G_{\mathrm{ads}}=\Delta G_{\mathrm{disp}}+\Delta G_{\mathrm{spec}}$

As alkanes have no special functionality, they only exhibit dispersive interactions with the silica substrate. This property is useful in determining the remaining contribution of the specific interactions of functionalized substances to the total free energy of adsorption by measuring the net retention volume $V_{N}^{\prime}$ for each probe solute. When plotting $R T \ln \left(V_{\mathrm{N}}{ }^{\prime}\right.$ ) (in $\mathrm{kJ} / \mathrm{mol}$ units, where $R$ is the universal gas constant and $T$ is the column temperature) versus the logarithm of the saturated vapor pressure, a straight line is obtained for the $n$-alkanes. Then, $\Delta G_{\text {spec }}$ of a functionalized solute can be obtained by measuring the vertical distance from the point of this solute to the $n$-alkane reference line (see Figure 1 ). The slope of the $n$-alkane reference line represents the change in the free energy of adsorption per methylene group in the $n$-alkanes, $\Delta G_{\mathrm{CH} 2}$. This parameter can be used as a measure of the dispersive component $\gamma_{S}^{\mathrm{D}}$ of the surface

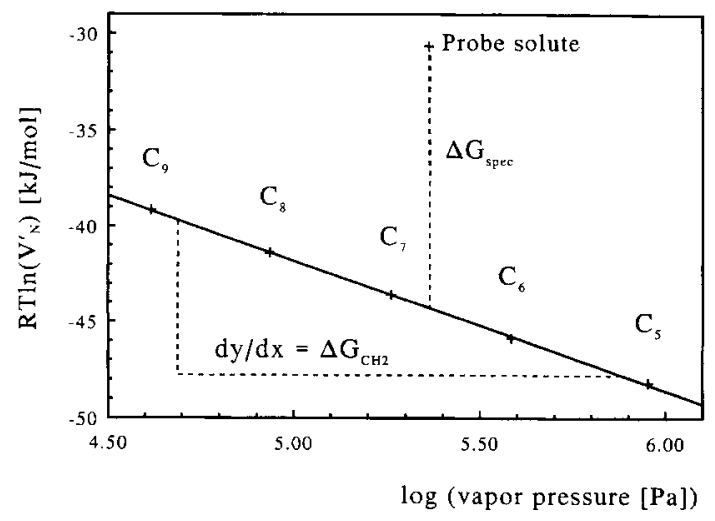

Figure 1

Plot of $R T \ln \left(V^{\prime} N\right)$ versus the logarithm of the vapor pressures of $n$-alkanes from which the free specific energy of adsorption, $\Delta G_{\mathrm{spec}}$, can be determined. energy of the solid phase, as these parameters are directly linked through equation (2)

$\Delta G_{\mathrm{CH} 2}=2 \mathrm{Na} \sqrt{\gamma_{\mathrm{S}}^{\mathrm{D}} \gamma_{\mathrm{L}}}$

in which $N$ is Avogadro's number, a the area of an adsorbed methylene group, and $\gamma_{\mathrm{L}}$ the surface energy of the alkane liquid.

\section{$2.2{ }^{29} \mathrm{Si}$ CP MAS NMR}

To be able to understand the chromatographic behavior of a stationary phase, it is absolutely necessary to know the chemical composition of the surface. ${ }^{29} \mathrm{Si}$ cross-polanization magic-anglespinning nuclear magnetic resonance is a powerful tool for determining surface structures of silicas because of its surface selectivity. This selectivity is introduced by the cross-polarization process in which magnetization is transferred from protons to silicon nuclei not more than four chemical bonds away. As protons usually (but not exclusively!) occur at the outer surface of silicas, only the silicon nuclei close to the surface are involved in cross-polarization. ${ }^{29} \mathrm{Si}$ NMR signals of silicas are fairly broad due to the amorphous nature of the solid in which site dispersion occurs. This causes a spread in the chemical shifts of ${ }^{29} \mathrm{Si}$ nuclei of a certain type.

Figure 2 shows the chemical surface structures present on trimethylsilylated silica that can be separately detected by ${ }^{29} \mathrm{Si} \mathrm{CP}$ MAS NMR, together with their isotropic chemical shifts and the abbreviations that will be used further on to designate the different types of surface silanols.

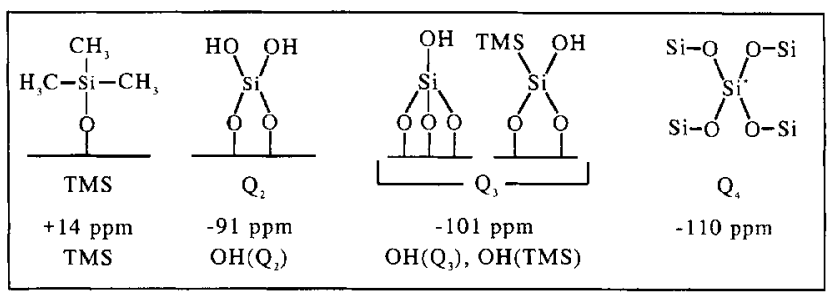

Figure 2

Chemical structures present at silica surfaces after reaction with trimethylchlorosilane. NMR chemical shifts are referenced externally to tetramethylsilane. Also listed are the abbreviations for specifying the different types of silanols.

\section{Materials and Methods}

\subsection{Materials}

Aerosil A-200 (Degussa AG, Frankfurt, Germany) with an average particle diameter of $12 \mathrm{~nm}$ and a specific surface area of $200 \mathrm{~m}^{2} / \mathrm{g}$ was used as the fused silica model substrate.

Probe solutes for the IGC experiments, including the $n$-alkanes pentane, hexane, heptane, octane, and nonane, were purchased from different suppliers and used as received (Table 1).

\subsection{Preparation of Trimethylsilylated Aerosil}

The Aerosil particles were first dehydrated by heating at $740^{\circ} \mathrm{C}$ for 48 hours. This treatment is necessary to remove any internal silanol groups that do not take part in the chromatographic process, but that would be detected by ${ }^{29} \mathrm{Si}$ CP MAS NMR. Then the surface of the particles was rehydrated by refluxing in pure water (Milli-O water purification system, Millipore Corporation) for 6 hours. The water was removed in a rotary evaporator and the rehydrated Aerosil was dried for 6 hours at $110-120^{\circ} \mathrm{C}$ in a vacuum desiccator. 
Table 1

Probe solutes for the inverse gas chromatographic experiments.

\begin{tabular}{lll}
\hline Probe solute & Functionality & $\begin{array}{l}\log \left(P_{0}\right) \\
\left.(P \text { in } \mathrm{Pa})^{\mathrm{a}}\right)\end{array}$ \\
\hline Heptane & - & 5.263 \\
1-Heptene & $-\mathrm{C}=\mathrm{C}$ & 5.319 \\
1-Chloropentane & $-\mathrm{C}-\mathrm{Cl}$ & $5.177^{\mathrm{b})}$ \\
Toluene & Aromatic & 5.118 \\
Propanenitrile & $-\mathrm{CN}$ & 5.274 \\
Dipropyl ether & $-\mathrm{C}-\mathrm{O}-\mathrm{C}-$ & 5.363 \\
3-Pentanone & $\mathrm{C}=\mathrm{O}$ & 5.224 \\
\hline
\end{tabular}

a) From ref. 14

b) Obtained through interpolating the linear relationship between $\log \left(P_{0}\right)$ and the homologue numbers of 1 -chloropropane to 1 -chlorononane.

The silanol surface concentration after this treatment is $8.45 \pm 0.15 \mu \mathrm{mol} / \mathrm{m}^{2}$ [15]. The phases A1, A2, A3, and A4 were prepared from the rehydrated Aerosil ( $\mathrm{A} 0$ ) by adding respectively $25,68.5,130$, and $1,130 \mu \mathrm{l}$ trimethylchlorosilane $(98 \%$, Aldrich Milwaukee, Wisconsin, USA) to a suspension of $2 \mathrm{~g}$ A0 in $20 \mathrm{ml}$ dry dichloromethane (HPLC grade, Westburg, Leusden, The Netherlands, distilled over $\mathrm{P}_{2} \mathrm{O}_{5}$ ). The suspensions were refluxed for 5 hours under an inert argon atmosphere according to a procedure described by Kinkeland Unger for the silanization reaction of silicas for RP-HPLC phases with alkylchlorosilanes [16]. The dichloromethane was removed using a rotary evaporator and the products were again dried for 6 hours at $110-120^{\circ} \mathrm{C}$ under vacuum and stored over phosphorus pentoxide. The weight percentage carbon of the phase A3 was determined on a Perkin Elmer (Beaconsfield, England) Elemental Analyzer Model 240. The percentage carbon of the phases $A 1, A 2$, and $A 4, \% C^{A x}$ (where $x$ denotes the phase number), were calculated according to equation (3),

$\% C^{\mathrm{Ax}}=\% C^{\mathrm{A} 3} \times \frac{N_{\mathrm{TMS}}^{\mathrm{Ax}}}{N_{\mathrm{TMS}}^{\mathrm{A} 3}}$

in which $N_{\text {TMS }}^{\text {Ax }}$ is the absolute area of the trimethylsiloxysilane NMR signal. Care was taken to ensure this peak area to be a reliable quantitative measure of the TMS surface coverage. Therefore, peak area ratios were checked at two different contact times (vide infra) and they appeared to show no significant difference.

\subsection{Inverse Gas Chromatography}

All chromatographic experiments were performed on a Varian 3400 Gas Chromatograph (Varian, Sunnyvale, California, USA) equipped with a flame ionization detector. Helium was used as the carrier gas. A Perkin Elmer Nelson Model 1020 data system was used for data collection and processing.

Glass columns with a length of $20 \mathrm{~cm}$ and an inner diameter of 0.14 $\mathrm{cm}$ were packed with Aerosil powder. Columns were weighed before and immediately after packing. Alkanes yielded symmetrical elution signals (see Figure $\mathbf{3}$ ), indicating that regular packings were obtained. No extra adsorption activity could be detected from the glass wall or the small plug of silanized glass wool (Perkin Elmer, Norwalk, Connecticut, USA) that was used to keep the Aerosil in place. This was checked by comparing elution profiles of dibutyl ether on respectively an empty column, a column with silanized glass wool at the outlet and on a dynamically, polymethylsilicone coated column with and without silanized glass wool. Freshly packed columns were conditioned for at least 12 hours at $120^{\circ} \mathrm{C}$

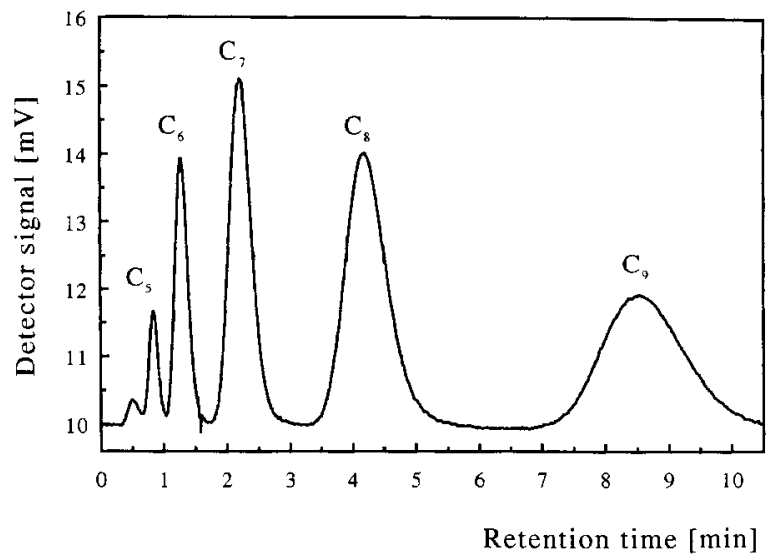

Figure 3

Example of a typical chromatogram of the $n$-alkanes $C_{5}-C_{9}$, used to construct a $n$-alkane reference line. Column: $130.1 \mathrm{mg} \mathrm{A0}$. Flow rate: $2.16 \mathrm{ml} / \mathrm{min}$. Inlet pressure: 27 p.s.i.

under a helium flow. Experiments were performed at $120^{\circ} \mathrm{C}$. Methane was used as the dead time marker.

\subsubsection{IGC at Finite Concentration}

The inlet pressure was held constant at 75 psi, resulting in helium flows varying from 1 to $10 \mathrm{ml} / \mathrm{min}$. Volumes ranging from $0.4 \mu \mathrm{l}$ for heptane to $8 \mu \mathrm{l}$ for 3 -pentanone were injected with a Hamilton microliter syringe. Flow rates were determined with a soap bubble flow meter and corrected for temperature differences. The sensitivity $S$ of the FID was calculated in As/mol units from the total peak area and the injected amount in moles. For the conversion of detector signal height to gas phase concentration equation (4) was used,

Gas phase concentration $=\frac{H R}{S F}$

where $H$ is the height of the detector $\operatorname{signal}(V), R$ is the range factor $(A N), S$ is the sensitivity, and $F$ is the flow rate $\left(\mathrm{m}^{3} / \mathrm{s}\right)$. Then the ECP theory could be applied to calculate the amount adsorbed in equilibrium with this gas phase concentration. The following factors influencing isotherm measurements were taken into account: a) sorption effect; b) gas compressibility; c) dependence of the isotherm on total pressure; d) gas imperfection [13].

\subsubsection{IGC at Infinite Dilution}

A gaseous mixture of the $n$-alkanes was injected (Figure 3 ) to construct the $n$-alkane reference line. Injection volumes for probe solutes were kept as small as possible to ensure infinite dilution conditions. Ideally the peak maxima did not exceed 10 times the detector noise level (Figure 4). Net retention volumes $V_{\mathrm{N}}{ }^{\prime}$ were calculated using equation (5),

$V_{N^{\prime}}=\frac{3}{2} \times\left[\frac{\left(P_{\mathrm{i}} / P_{\mathrm{O}}\right)^{2}-1}{\left(P_{\mathrm{i}} / P_{\mathrm{O}}\right)^{3}-1}\right] F_{\mathrm{C}} t_{\mathrm{r}}^{\prime}$

where $P_{1}$ is the inlet pressure, $P_{0}$ the outlet pressure, $F_{\mathrm{C}}$ is the temperature corrected flow rate, and $t_{\mathrm{r}}$ is the net retention time. The retention volumes of each probe solute on every phase were measured twice to check for reproducibility and reliability of the correction factors. First, all chromatographic runs were done at an inlet pressure of 75 psi. Next the experiments were repeated at a constant flow rate of approximately $2 \mathrm{ml} / \mathrm{min}$. 


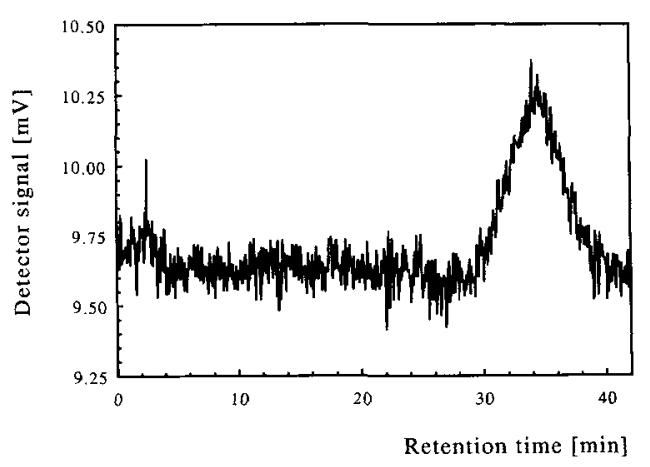

Figure 4

Chromatogram of propanenitrile at infinite dilution conditions. Column: 188.6 $\mathrm{mg} \mathrm{A0}$. Flow rate: $10.5 \mathrm{ml} / \mathrm{min}$. Inlet pressure: 75 p.s.i.

\section{$3.4{ }^{29} \mathrm{Si}$ CP MAS NMR}

Spectra were collected on a Bruker MSL-400 NMR spectrometer at 79.6 $\mathrm{MHz}$ (Bruker Analytik GmbH, Rheinstetten, Germany). The magic angle spinning frequency was $2000 \mathrm{~Hz}$. The contact times used in this work were 6 and 12 milliseconds. The acquisition time was $10 \mathrm{~ms}$ and the pulse interval time was set to $4 \mathrm{~s}$. Typically, 3000 free induction decays were added in $1 \mathrm{~K}$ data points. Prior to Fourier Transformation, the FID's were zerofilled to 8K and a line broadening of $20 \mathrm{~Hz}$ was applied. To estimate the concentration ratios of the different surface structures, the spectra were simulated using the Bruker LINESIM program. The absolute peak area of the trimethylsiloxysilane signal of the phase $\mathrm{A} 3\left(N_{\mathrm{TMS}}^{\mathrm{A3}}\right)$ was calculated in area per gram units and used for calculating the percentages of carbon in the other phases (Equation 3).

\subsection{Calculation of Surface Concentrations}

The surface concentration of trimethylsilyl groups (denoted by $\Gamma_{\mathrm{TMS}}$ in $\mu \mathrm{mol} / \mathrm{m}^{2}$ can be calculated directly from the percentage carbon of a phase, the atomic weight of carbon and the specific surface area $S_{\mathrm{A}}$ (Equation 6).

$\Gamma_{\mathrm{TMS}}^{\mathrm{Ax}}=\frac{10,000 \% C^{\mathrm{Ax}}}{3 \times 12.01 S_{\mathrm{A}}}$

When a few assumptions are made, the absolute surface concentration of all chemical surface structures can be calculated. First of all, in the calculation a total surface concentration of hydroxyl groups on the phase $A 0$ of $8.45 \mu \mathrm{mol} / \mathrm{m}^{2}[15]$ is used. Furthermore, it is assumed that $\mathrm{O}_{2}$ groups are not capable of binding more than one trimethylsilyl moiety because of severe steric limitations. This means that after a certain degree of trimethylsilylation equation (7) holds. The subscripts to $\Gamma$ indicate the type of silanol specified.

$8.45-\Gamma_{\mathrm{TMS}}^{\mathrm{Ax}}=\Gamma_{\mathrm{OH}\left(\mathrm{O}_{2}\right)}^{\mathrm{Ax}}+\Gamma_{\mathrm{OH}\left(\mathrm{O}_{3}\right)}^{\mathrm{Ax}}+\Gamma_{\mathrm{OH}(\mathrm{TMS})}^{\mathrm{Ax}}$

Realizing that $\mathrm{Q}_{2}$ groups bear two surface hydroxyls, the ratio of the NMR peak area $\mathrm{O}_{2} / \mathrm{O}_{3}$ can be written as

$\left(\frac{Q_{2}}{Q_{3}}\right)^{\mathrm{Ax}}=\frac{1}{2} \times \frac{\Gamma_{\mathrm{OH}\left(\mathrm{O}_{2}\right)}^{\mathrm{Ax}}}{\Gamma_{\mathrm{OH}\left(\mathrm{O}_{3}\right)}^{\mathrm{Ax}}+\Gamma_{\mathrm{OH}(\mathrm{TMS})}^{\mathrm{Ax}}}$

Rearranging and combining equations (7) and (8) gives:

$$
\Gamma_{\mathrm{OH}\left(\mathrm{O}_{2}\right)}^{\mathrm{Ax}}=\frac{8.45-\Gamma_{\mathrm{TMS}}^{\mathrm{Ax}}}{\left[1+\frac{1}{2}\left(\frac{\mathrm{Q}_{3}}{\mathrm{O}_{2}}\right)^{\mathrm{Ax}}\right]}
$$

As the surface concentration of silanols of the $\mathrm{O}_{2}$ type on the phase $\mathrm{AO}$ is known from the NMR ratio $\mathrm{O}_{2} / \mathrm{O}_{3}$ and the total silanol surface concentration, the number of $\mathrm{O}_{2}$ groups that has reacted with trimethylchlorosilane can be obtained via equation (10):

$\Gamma_{\mathrm{OH}(\mathrm{TMS})}^{\mathrm{Ax}}=\frac{1}{2}\left(\Gamma_{\mathrm{OH}\left(\mathrm{O}_{2}\right)}^{\mathrm{AO}}-\Gamma_{\mathrm{OH}\left(\mathrm{Q}_{2}\right)}^{\mathrm{Ax}}\right)$

The concentration of TMS moieties that have reacted with former $\mathrm{O}_{3}$ silanols $\left(\Gamma_{\mathrm{TMS}}\right)$ is now given by

$\Gamma_{\mathrm{TMS}\left(\mathrm{O}_{3}\right)}^{\mathrm{Ax}}=\Gamma_{\mathrm{TMS}}^{\mathrm{Ax}}-\Gamma_{\mathrm{OH}(\mathrm{TMS})}^{\mathrm{Ax}}$

Finally, $\Gamma_{\mathrm{OH}\left(\mathrm{Q}_{3}\right)}$ can be obtained by rearranging equation (7).

\section{Results and Discussion}

In Figure 5 the ${ }^{29} \mathrm{Si} \mathrm{CP} \mathrm{MAS} \mathrm{NMR} \mathrm{spectra} \mathrm{of} \mathrm{the} \mathrm{phases} \mathrm{A0,} \mathrm{A1,}$ $A 2, A 3$, and $A 4$ are shown. Most prominent is the increase of the trimethylsilyl signal at $+14 \mathrm{ppm}$ and the concomitant decrease of the silanol signals of $\mathrm{Q}_{2}$ at $-91 \mathrm{ppm}$ and of $\mathrm{O}_{3}$ at $-101 \mathrm{ppm}$. In the spectrum of A4 a small peak at -21.2 ppm occurs, which we think is due to a contamination of the trimethylchlorosilane with dimethyldichlorosilane. The large excess used in preparing phase A4 led to a relatively high concentration of the more reactive dimethyldichlorosilane [17], causing the formation of dimethyldisiloxysilane surface structures resonating at $-21 \mathrm{ppm}$. For the phases $A 1, A 2$, and $A 3$ the product of relative concentration and relative reactivity of the dichlorodimethylsilane contaminant apparently was too small for a significant difunctional silylation to occur.

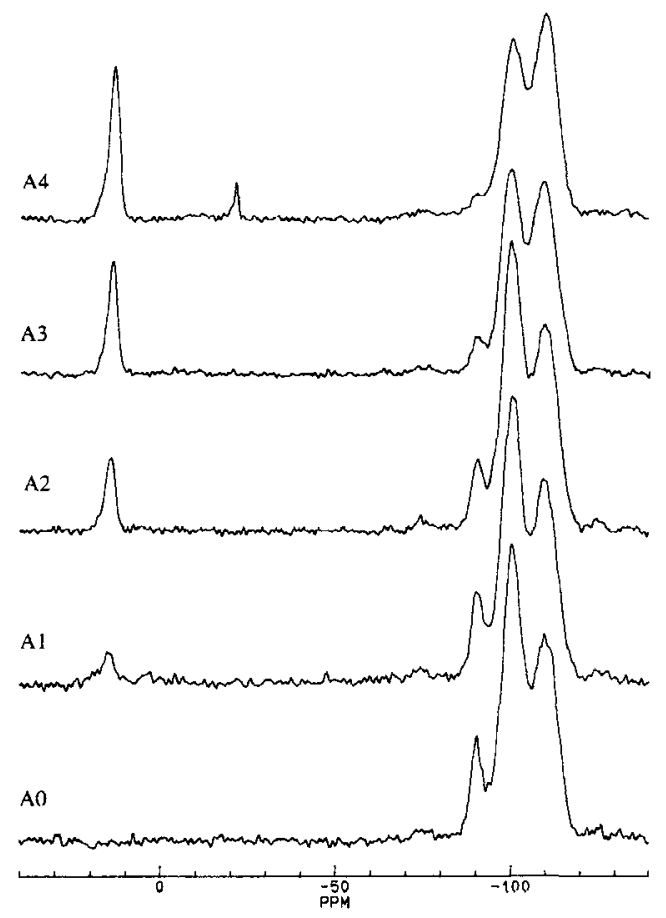

Figure 5

${ }^{29} \mathrm{Si}$ CP MAS NMR spectra of the Aerosil phases. 
Table 2

Combined results of ${ }^{29} \mathrm{Si}$ CP MAS NMR and elemental analysis and the calculated surface concentrations. Values are indicated together with their estimated absolute standard deviation.

\begin{tabular}{|c|c|c|c|c|c|}
\hline & AO & A1 & $\begin{array}{r}\text { Phases } \\
\text { A2 }\end{array}$ & A3 & $A 4^{\mathrm{a})}$ \\
\hline$\% \mathrm{C}$ & 0 & $0.33 \pm 0.02$ & $0.84 \pm 0.05$ & $1.52 \pm 0.03^{b)}$ & $2.57 \pm 0.15$ \\
\hline $\mathrm{O}_{2} / \mathrm{O}_{3}$ & $0.216 \pm 0.004$ & $0.216 \pm 0.004$ & $0.166 \pm 0.003$ & $0.127 \pm 0.002$ & $0.062 \pm 0.002$ \\
\hline
\end{tabular}

Calculated surface concentrations in $\mathrm{mol} / \mathrm{m}^{2}$ (Relative decreases with respect to $\mathrm{A} 0$ in parentheses).

\begin{tabular}{|c|c|c|c|c|c|}
\hline$\Gamma_{\mathrm{OH}(\mathrm{O} 2)}$ & $2.55 \pm 0.05$ & $\begin{array}{c}2.41 \pm 0.06 \\
(-5 \%)\end{array}$ & $\begin{array}{c}1.82 \pm 0.06 \\
(-29 \%)\end{array}$ & $\begin{array}{c}1.28 \pm 0.04 \\
(-50 \%)\end{array}$ & $\begin{array}{c}0.54 \pm 0.04 \\
(-79 \%)\end{array}$ \\
\hline$\Gamma_{\mathrm{OH}(\mathrm{O} 3)}$ & $5.90 \pm 0.11$ & $\begin{array}{c}5.5 \pm 0.2 \\
(-7 \%)\end{array}$ & $\begin{array}{c}5.1 \pm 0.2 \\
(-14 \%)\end{array}$ & $\begin{array}{c}4.5 \pm 0.2 \\
(-24 \%)\end{array}$ & $\begin{array}{c}3.4 \pm 0.3 \\
(-43 \%)\end{array}$ \\
\hline$\Gamma_{\mathrm{OH}(\mathrm{TMS})}$ & 0 & $0.11 \pm 0.05$ & $0.40 \pm 0.05$ & $0.59 \pm 0.05$ & $0.96 \pm 0.05$ \\
\hline$\Gamma_{\mathrm{TMS}}$ & 0 & $0.45 \pm 0.03$ & $1.17 \pm 0.07$ & $2.11 \pm 0.04$ & $3.6 \pm 0.2$ \\
\hline
\end{tabular}

a) The peak area of the contamination at $-21 \mathrm{ppm}$ in the NMR spectrum was considered as stemming from trimethylsilyl moieties

${ }^{b)}$ Average of 7 elemental analyses.

Table 2 shows the combined results of the NMR peak simulations and elemental analysis. Also listed are the calculated surface concentrations. From a comparison of the relative decreases in $\Gamma \mathrm{OH}(\mathrm{Q} 2)$ and $\Gamma_{\mathrm{OH}}(\mathrm{O} 3)$ it follows that at low surface coverage there is no significant difference between $\mathrm{O}_{2}$ silanols and $\mathrm{O}_{3}$ silanols in reactivity towards trimethylchlorosilane. At higher degrees of trimethylsilylation, $\mathrm{O}_{2}$ silanols are more likely to be silylated.
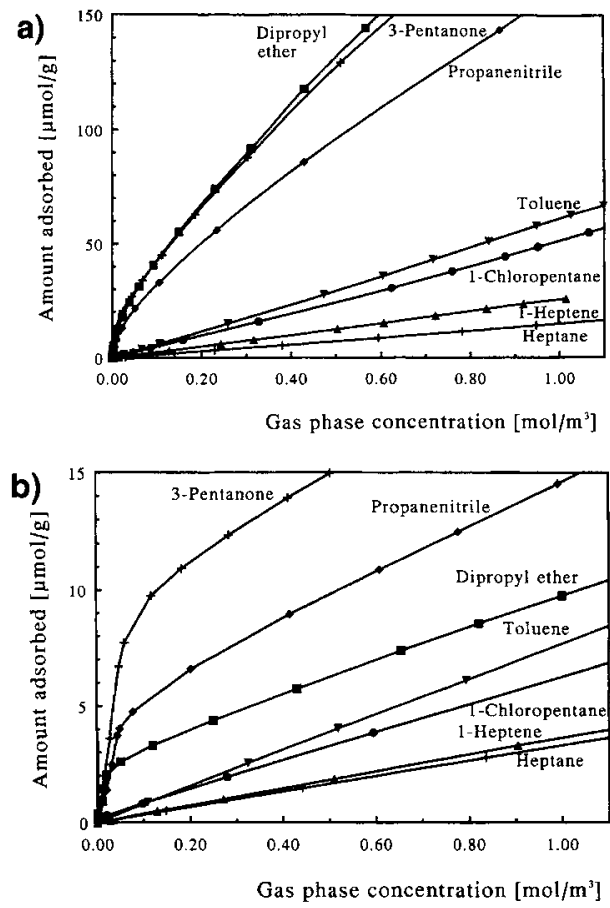

Figure 6

ECP-isotherms of the probe solutes, a) on the phase $\mathrm{AO}, \mathrm{b}$ ) on the phase A4.
In Figures $6 \mathbf{a}$ and $\mathbf{6 b}$ the adsorption isotherms of the probe solutes on the phases $\mathrm{AO}$ and $\mathrm{A} 4$ are shown to illustrate the results of the ECP method. To obtain reliable and exact isotherms from an elution profile, the theoretical plate number of the column should be at least 6000 [18]. The plate number of the columns used in this study was only about 200 , indicating that the calculated isotherms are no more than rough approximations of the true distribution isotherms. Nevertheless, they can be used for some qualitative considerations.

The isotherms for all probes on the non-silylated phase A0 are determined by specific interactions with surface silanol groups. As can be seen from Figure 6a, the process of hydrogen bonding apparently involves high specific adsorption energies. The isotherms of 3-pentanone, dipropyl ether, and propanenitrile have a much steeper initial slope than those of the other three test components incapable of forming hydrogen bonds. On a hypothetical $100 \%$ deactivated, completely homogeneous surface, the initial slope of the isotherms is only determined by dispersive interactions as specific interactions can no longer occur. However, at maximum trimethylsilylation, the conversion of surface silanols to trimethylsilyl groups will at best be $70 \%$ [2]. This means that all the phases considered here have an inhomogeneous surface, consisting of relatively inert trimethylsilyl groups and relatively active residual silanol sites. The features of the isotherms of the hydrogen bonding probes on phase A4 reflect this surface inhomogeneity. At low gas-phase concentrations, the active silanol sites are still available for interaction and the initial slopes of the isotherms are fairly steep. At increased gas-phase concentrations, saturation of the hydrogen bonding sites starts to occur. In this region strongly curved isotherms are observed. At still higher gas phase concentrations, no more silanol groups are available for interaction and the slopes of the isotherms start to resemble those of the other non-hydrogen bonding probe solutes

More quantitative information was obtained from the results of inverse chromatography at infinite dilution. Correlation coefficients of the $n$-alkane reference lines were better than 0.999 and specific interaction energies obtained from separate measurements were 


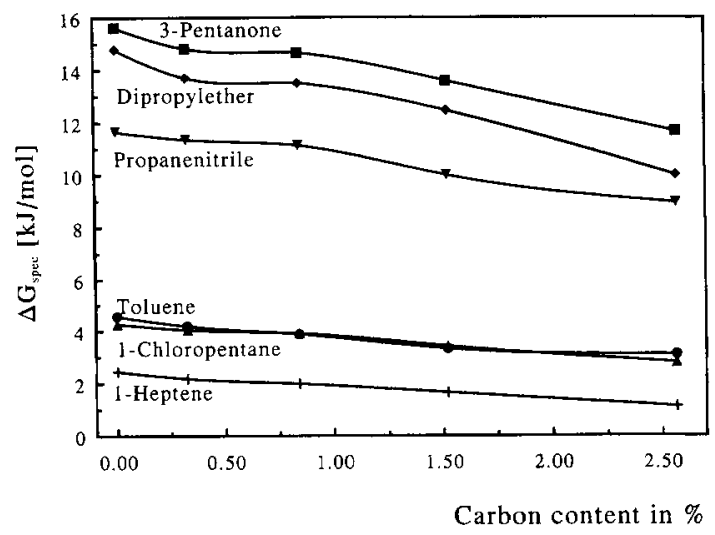

Figure 7

The free specific energies of adsorption, $\Delta G_{s p e c}$, of the probe solutes as a function of the carbon content of the silylated Aerosil phases.

reproducible within a relative error of $3 \%$. Figure 7 shows the absolute values of the free specific energies of adsorption for all probe solutes as a function of the carbon content of the stationary phase. The free specific energies of adsorption of the hydrogen bonding probes to the Aerosil surface are at least $6 \mathrm{~kJ} / \mathrm{mol}$ higher than those of the other probe solutes.

Knowing the surface concentrations of the different chemical surface structures (Table 2) and the specific adsorption energy for each probe on the five phases, the contribution of each type of adsorption site to the total free specific energy of adsorption can be determined Assuming that due to the maximized silanol surface concentration of phase A0, siloxane bridges play only a minor role in the adsonption processes occurning at the surface, equation (12) shows how this can be achieved.

$$
\begin{aligned}
& 8.45 e^{\Delta G_{\mathrm{spec}} / R T}=\Gamma_{\mathrm{OH}\left(\mathrm{O}_{2}\right)} e^{\varepsilon_{\mathrm{OHO}_{2} / R T}}+\Gamma_{\mathrm{OH}\left(\mathrm{O}_{3}\right)} e^{\varepsilon_{\mathrm{OHO}} / R T}+ \\
& +\Gamma_{\mathrm{OH}(\mathrm{TMS})} \mathrm{e}^{\varepsilon_{\mathrm{OH}(T M S)} / R T}+\Gamma_{\mathrm{TMS}} \mathrm{e}^{\varepsilon_{\mathrm{TMS}} / R T}
\end{aligned}
$$

This equation states that the product of the total number of adsorption sites and the average residence time on a surface site due to specific asorption [which is proportional to $\exp \left(\Delta G_{\text {sped }} / R T\right)$ ] is equal to the sum of the products of concentration and residence times specified for all surface species. As a working hypothesis it is assumed that the free specific energy of adsorption for a given chemical surface structure is not a function of the degree of trimethylsilylation, a prerequisite for solving equation (12). By writing this equation for all five different phases, each chromatographically characterized twice, a set of ten linear equations is obtained with the specific interaction energies of the separate surface structures as variables. With a least squares solution of this overdetermined set of equations, the variables were determined. Table $\mathbf{3 a}$ lists the outcome of performing the regression calculation for all probe solutes. The values for the free specific energy of adsorption are given, together with their $90 \%$ confidence intervals. This approach leads to potentially important conclusions. It appears that only for propanenitrile the calculated values for the four chemical surface structures are significantly different. The residual silanols that remain after reaction of $\mathrm{a}_{2}$ group with trimethylchlorosilane have an adsorption activity that is two to three times larger than the activity of the $\mathrm{O}_{2}$ silanols initially present. Silanols of the $\mathrm{Q}_{3}$ type appear less active in adsorption.
Although statistically speaking the numerical values of $\varepsilon$ do not differ significantly for the other probe solutes, after arranging the surface structures in descending order of adsorption activity according to these calculated values, there appears to be a consistent ordering for all probe solutes (Table 3b). The OH(TMS) functionality is the one with the highest adsorption activity. As expected, TMS moieties have the smallest contribution to the free specific energy of adsorption.

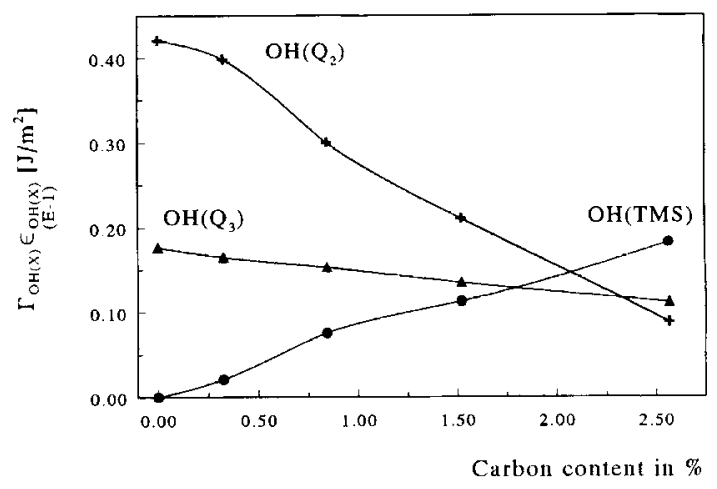

Figure 8

Contributions of the three different types of silanol functionalities to the total free specific energy of adsorption of propanenitrile.

Figure 8 displays the contribution of the various types of surface structures to the total free specific energy of adsorption for propanenitrile. The abscissa units are given in Joules per square meter phase by multiplying $\Delta \varepsilon_{\mathrm{OH}(\mathrm{X})}$ (in $\mathrm{kJ} / \mathrm{mol}$ ) by the surface concentration of the specified silanol structure (in $\left.\mu \mathrm{mol} / \mathrm{m}^{2}\right)$. The curves illustrate that while the contributions of $\mathrm{Q}_{2}$ and $\mathrm{Q}_{3}$ functionalities to the total specific adsorption activity of the Aerosil surface decrease upon trimethylsilylation, the contribution of the more active OH(TMS) moieties increases. This increasing contribution of $\mathrm{OH}(\mathrm{TMS})$ functionalities sets an upper limit to the deactivation of silica surfaces through trimethylsilylation. In short, the majority of the silanol groups present at the native silica are silylated upon maximum trimethylsilylation, but upon silylation of $\mathrm{Q}_{2}$ groups silanol functionalities are formed that are more active in adsorption than those initially present. Recently Takeuchi et al. reported that the number of residual silanol groups in silica-based packings for liquid chromatography was overestimated when using the retention of benzene relative to cyclohexane under $\mathrm{GC}$ conditions as a measure of the silanol population [20]. Our result gives an indication that this is caused by the higher average free specific energy of adsorption to these residual silanol sites compared to the silanols present on the native silicas.

The data in Table 3 a were subjected to a ruggedness test in which all parameters in the equations (6-11) were varied between their extremes. The results in Table 3 appeared to be largely unaffected by these variations. Hence, the large spread in the $\varepsilon$ values in Table 3a indicates the limited applicability of our working hypothesis (vide supra for justification). This is most easily illustrated in the case of toluene by means of Figure $\mathbf{9}$. There the relative free specific energy of adsorption is displayed, after arbitrarily setting the value for the phase A0 to $100 \%$. Toluene (and 1-heptene) show the fastest decrease, which is plausible if it is assumed that the energetically most favorable adsorption of these solutes is achieved when the aromatic ring (or the $\pi$ bond, respectively) is coordinated parallel to the silica surface. When part of the surface is trimethylsilylated, these coordinations are sterically too demanding and the interac- 
Table 3

a: Specific energies of adsorption per type of chemical surface structure in $\mathrm{kJ} / \mathrm{mol}$ with their $90 \%$ confidence interval

$\begin{array}{lllll}\varepsilon[\mathrm{kJ} / \mathrm{mol}] & \mathrm{OH}\left(\mathrm{O}_{2}\right) & \mathrm{OH}\left(\mathrm{O}_{3}\right) & \mathrm{OH}(\mathrm{TMS}) & \mathrm{TMS}\end{array}$

$\begin{array}{lcccc}\text { 1-Heptene } & 3 \pm 3 & 1.8 \pm 1.8 & 4 \pm 4 & 1.5 \pm 1.5 \\ \text { 1-Chloropentane } & 7 \pm 2 & 2 \pm 2 & 9 \pm 3 & 0 \\ \text { Toluene } & 6 \pm 4 & 3 \pm 3 & 6 \pm 6 & 4 \pm 4\end{array}$

Propanenitrile

$16.5 \pm \quad 1.5$

$3 \pm 3$

$19.1 \pm 1.5$

0

Dipropyl ether

$10 \pm 10$

$9 \pm 9$

$12 \pm 12$

$8 \pm 8$

3-Pentanone

$11 \pm 11$

$9 \pm 9$

$12 \pm 12$

$8+8$

b: Surface structures ordered in descending specific energy of adsorption

\begin{tabular}{|c|c|c|c|c|c|c|c|}
\hline 1-Heptene & $\mathrm{OH}(\mathrm{TMS})$ & $\approx$ & $\mathrm{OH}\left(\mathrm{O}_{2}\right)$ & $\approx$ & $\mathrm{OH}\left(\mathrm{O}_{3}\right)$ & $\approx$ & TMS \\
\hline 1-Chloropentane & $\mathrm{OH}(\mathrm{TMS})$ & $\approx$ & $\mathrm{OH}\left(\mathrm{O}_{2}\right)$ & $>$ & $\mathrm{OH}\left(\mathrm{O}_{3}\right)$ & $>$ & TMS \\
\hline Toluene & $\mathrm{OH}\left(\mathrm{Q}_{2}\right)$ & $\approx$ & $\mathrm{OH}(\mathrm{TMS})$ & $\approx$ & $\mathrm{OH}\left(\mathrm{O}_{3}\right)$ & $\approx$ & TMS \\
\hline Propanenitrile & $\mathrm{OH}(\mathrm{TMS})$ & $\geq$ & $\mathrm{OH}\left(\mathrm{O}_{2}\right)$ & $>$ & $\mathrm{OH}\left(\mathrm{O}_{3}\right)$ & $>$ & TMS \\
\hline Dipropyl ether & $\mathrm{OH}(\mathrm{TMS})$ & $\approx$ & $\mathrm{OH}\left(\mathrm{O}_{3}\right)$ & $\approx$ & $\mathrm{OH}\left(\mathrm{O}_{2}\right)$ & $\approx$ & TMS \\
\hline 3-Pentanone & $\mathrm{OH}(\mathrm{TMS})$ & $\approx$ & $\mathrm{OH}\left(\mathrm{O}_{3}\right)$ & $\approx$ & $\mathrm{OH}\left(\mathrm{O}_{2}\right)$ & $\approx$ & TMS \\
\hline
\end{tabular}

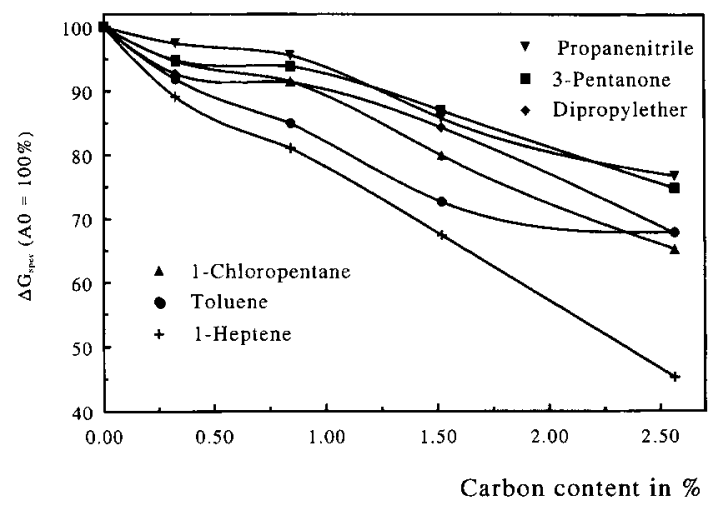

Figure 9

The free specific energies of adsorption, $\Delta \boldsymbol{G}_{\mathrm{spec}}$, for all probe solutes as a function of the carbon content of the Aerosil phases, relative to the value of $\Delta G_{\text {spec }}$ on the phase $A 0$.

tion energies decrease rapidly. Furthermore, it must be realized that although the probe solutes used in this study each represent a class of fairly simple, functionalized compounds, it will be difficult to assign a certain functionality to a specific part of the molecule. For example, the role of the weakly acidic $\alpha$ protons in the coordination of 3-pentanone to the silica surface is unknown. The adsorption data measured or calculated must be regarded as a weighed average of all the possible modes of adsorption of a probe solute to the solid phase [19]. It is clear that, when different adsorption modes are possible, certain modes could be favored by introducing trimethylsilyl groups on the silica surface, thus changing the con- tribution to the free specific energy of adsorption of a single type of surface structure as a function of trimethylsilyl surface coverage. This may explain why the data for propanenitrile appear to be the most consistent. The propanenitrile molecule has only the nitrogen lone pair electrons as interaction center, accompanied by an inert hydrocarbon chain. This very likely restricts the number of possible modes of adsorption to the one in which the lone pair electrons interact with acidic silanols in a 1:1 fashion. Despite the fairly great inaccuracy in the calculated adsorption energies, the results clearly indicate the importance of the role played in adsorption processes by the residual silanol functionalities that remain after reaction of a $\mathrm{O}_{2}$ surface site with trimethylchlorosilane.

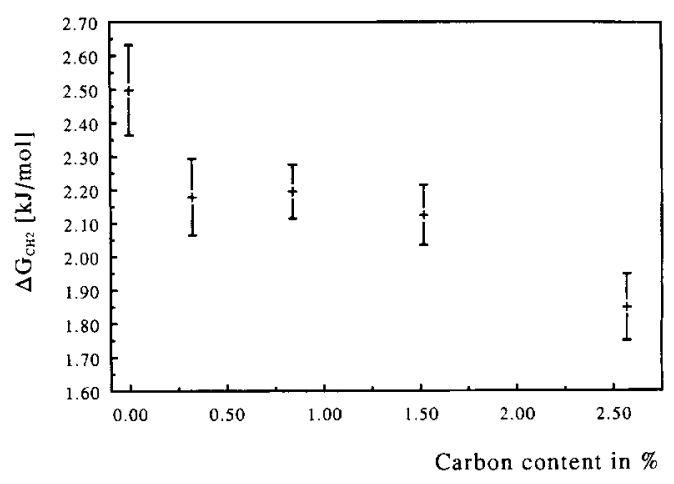

Figure 10

The change in free energy of adsorption per methylene group in the $n$-alkanes as a function of the carbon content of the Aerosil phases. The error bars indicate 3 times the standard deviation of the replicate measurements. 
Figure 10 gives the measured change in free energy of adsorption per methylene group in the $n$-alkanes as a function of the percentage carbon of the Aerosil phases. Although the expected decrease is observed, no meaningful curve can be fitted through the data points. This should be considered an illustration of the complex way in which even normal alkanes interact with inhomogeneous, silylated Aerosil surfaces.

\section{Conclusions}

Inverse gas chromatography is proven to be a helpful tool in characterizing the chromatographic properties of Aerosil, a model substrate for fused silica. The ECP isotherms show the surface inhomogeneity introduced by trimethylsilylation. IGC at infinite dilution yields specific adsorption energies for several probe solutes with an accuracy of $3 \%$ from which, in combination with ${ }^{29} \mathrm{Si} \mathrm{CP}$ MAS NMR data, specific free energies of adsorption per type of chemical surface structure can be calculated. Quantitative analysis indicates that residual silanols from the reaction of $\mathrm{O}_{2}$ groups are more active in adsorption than the silanols initially present at the silica surface. Probe solutes should unambiguously be monofunctional, because otherwise side effects in the adsorption mechanism will disturb the calculations of the free specific energy of adsorption per chemical surface structure.

\section{References}

[1] R.D. Dandeneau and E.H. Zerenner, J. High Resolut. Chromatogr. Chromatogr. Commun. 2 (1979) 351.

(2) J. Nawrocky, Chromatographia 31 (1991) 177.

[3] D.W. Sindorf and G.E. Maciel, J. Am. Chem. Soc. 102 (1980) 7606
[4] K. Albert and E. Bayer, J. Chromatogr. 544 (1991) 345.

(5) G. Rutten, A. van de Ven, J. de Haan, L. van de Ven, and J. Rijks, J. High Resolut Chromatogr. Chromatogr. Commun. 7 (1984) 607.

[6] A. Vidal, E. Papirer, Wang Meng Jiao, and J.B. Donnet, Chromatographia 23 (1987) 121.

[7] E. Papirer, A. Vidal, Wang Meng Jiao, and J.B. Donnet, Chromatographia $\mathbf{2 3}$ (1987) 279.

[8] E. Papirer, H. Balard, Y. Rahmani, A.P. Legrand, L. Facchini, and H. Hommel, Chromatographia 23 (1987) 639.

[9] E. Papirer, H. Balard, and A. Vidal, Eur. Polym. Sc. 8 (1988) 783.

[10] M. Sidq, G. Ligner, J. Jagiello, H. Ballard, and E Papirer, Chromatographia 28 (1989) 588 .

[11] G. Ligner, A. Vidal, H. Balard, and E. Papirer, J. Coll. Interf. Sc. 134 (1990) 486

(12] J. Roles and G. Guiochon, J. Chromatogr. 591(1992) 233.

[13] J. R. Conder and C.L. Young, "Physicochemical Measurements by Gas Chromatography", John Wiley \& Sons, Chichester (1979), chap 9.

[14] T. Boublík, V. Hála, and E. Fried, "The Vapour Pressures of Pure Substances", Elsevier, Amsterdam (1984) 2nd rev. edn.

[15] A. Tuel, H. Hommel, and A. P. Legrand, Langmuir 6 (1990) 770

[16] J.N. Kinkel and K.K. Unger, J. Chromatogr. 316 (1984) 193

[17] M.L. Hair and W. Hertl, J. Phys. Chem. 73 (1969) 2372

[18] J. Roles and G. Guiochon, J. Chromatogr. 591 (1992) 245

[19] J. Roles "An Inverse Gas-Solid Chromatographic Study of the Adsorption Heterogeneity of Aluminium Oxide Powders Used in Ceramic Processing." UMI, Ann Arbor MI, 1991, p. 7.

[20] T. Takeuchi, T. Miwa, and N. Nagae, Chromatographia 35 (1993) 375

Ms received: October 5, 1993 Accepted: October 9, 1993 